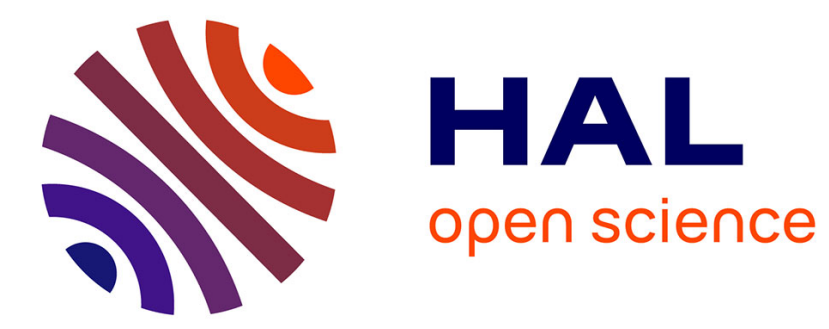

\title{
A General Analytical Expression for the Hysteresis Loop Description in Polycrystalline Soft Ferrites
}

\author{
F. Liorzou, K. Berthou-Pichavant, M. Le Floc'H
}

\section{To cite this version:}

F. Liorzou, K. Berthou-Pichavant, M. Le Floc'H. A General Analytical Expression for the Hysteresis Loop Description in Polycrystalline Soft Ferrites. Journal de Physique IV Proceedings, 1997, 07 (C1), pp.C1-205-C1-206. 10.1051/jp4:1997177 . jpa-00255124

\section{HAL Id: jpa-00255124 https://hal.science/jpa-00255124}

Submitted on 1 Jan 1997

HAL is a multi-disciplinary open access archive for the deposit and dissemination of scientific research documents, whether they are published or not. The documents may come from teaching and research institutions in France or abroad, or from public or private research centers.
L'archive ouverte pluridisciplinaire HAL, est destinée au dépôt et à la diffusion de documents scientifiques de niveau recherche, publiés ou non, émanant des établissements d'enseignement et de recherche français ou étrangers, des laboratoires publics ou privés. 


\title{
A General Analytical Expression for the Hysteresis Loop Description in Polycrystalline Soft Ferrites
}

\author{
F. Liorzou, K. Berthou-Pichavant and M. Le Floc'h \\ Laboratoire d'Électronique et des Systèmes de Télécommunications, UMR 1329, UFR Sciences, BP. 809, \\ 6 avenue Le Gorgeu, 29285 Brest cedex, France
}

\begin{abstract}
The initial form of the Globus model gives a good approach of the description of the macroscopic magnetic pro perties in polycrytalline soft ferrites by examining the motion of a flat $180^{\circ}$ domain wall inside a spherical grain. By the use of a new analytical expression of the magnetization curve calculated using this model, this work studies the effects of the grain shape on the theoretical curves of magnetization. We propose to take the grain outline as a new parameter for introducing a notion of magnetic hardness in the magnetization process. As an example, an experimental comparison between modelled and actual hysteresis loops is shown on polycrystalline YIG sample.
\end{abstract}

Assuming from a theoretical point of view that the ring-shaped polycrystalline soft magnetic matter could be considered as a true flux guide (the so-called "magnetic ring" concept), the Globus model gives a description of both reversible and irreversible mechanisms of magnetization in soft polycrystalline ferrites by examining the bowing and the displacement of a single $180^{\circ}$ domain wall inside an ideal spherical grain [1].

Starting from this model, we have proposed an analytical expression of the initial magnetization curve (by assuming that the initial position of the wall was the center of the spherical grain)[3]. We have next shown this expression may be easily extended to the representation of a magnetization curve issued from any remanent state. This conclusion has allowed us to propose an analytical formulation of the hysteresis loop as a function of only a few physical parameters, with the restriction that the formulation remained limited to small domain wall displacements round the diametral position [4].

The work we present here is concerned with the great magnetization changes. A new mathematical approach has been develloped which leads to express both the magnetization and magnetic field as a function of the domain wall position in the grain. The evaluation of the magnetic field $\mathrm{H}$ necessary to move the domain wall from its starting point ( $\mathrm{I}$ ) to the final state ( $\mathrm{P}$ ) (Fig.1.a), is done by minimizing the sum of three energies [2]. The first comes from the domain wall friction at the grain boundary. This energy is proportional to the wall circumference through the parameter $f$ (pinning force) which depends on both the microstructure and the intrinsic magnetic parameters. The second term denotes the variation of the domain wall surface, $\gamma$ being the wall energy density. The third term is the magnetostatic energy acting on the wall as a "magnetic pressure". As a result, the spontaneous magnetization $M s$, the grain radius $R, y$ and $f$ are the fitting parameters of the model. They depend on the material (chemical composition and microstructure). $\mathrm{H}$ is given as follows :

$$
H=\frac{f R d \theta+\gamma(R \cos \theta d \alpha+\sin \alpha d \rho)}{M_{S} \rho \sin \alpha(-\rho \sin \alpha d \alpha+(R / \rho) \cos \theta d \rho)}
$$

The magnetization is given by :

$$
M=(1 / 2) \cdot M s \cdot \cos \theta\left(2+\sin ^{2} \theta\right)
$$

Figure (1.b) shows two representations of this function [Eqs.(1) and (2)]. We can note that the magnetization curve outlines are closely connected to the wall position in the grain. An increase of the wall size ( in the left part of the grain) leads to a parabolic-like curve shape while a decrease of the wall size ( right part of the grain ) leads to a rather hyperbolic-like shape.This latter is typical of both the initial magnetization curve and the upper part of the loop side, and expresses the increasing difficulty for the wall to move as the magnetization rises. 
This paper proposes the grain shape as a new parameter to control the aptitude of the domain wall to move inside the grain. The influence of this parameter is shown in (Fig.1.c) where magnetization curves corresponding to different grain shapes are compared. The cube 1 gives rise to vertical sides when the wall is depinning because there is no change of its area during the movement. This behaviour is strikingly similar to those observed on amorphous thin films[5]. When the variation of the wall area is constant (cube 2) the curve keeps an hyperbolic-like shape. Qualitatively, the sphere appears to be the best solution to represent the actual polycrystalline material behavior. Furthemore, this spherical shape is a good choice for the average grain representation.

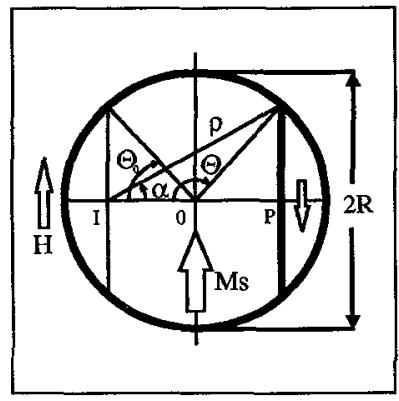

a)

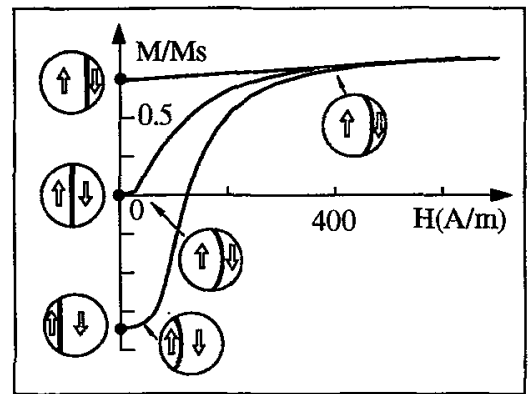

b)

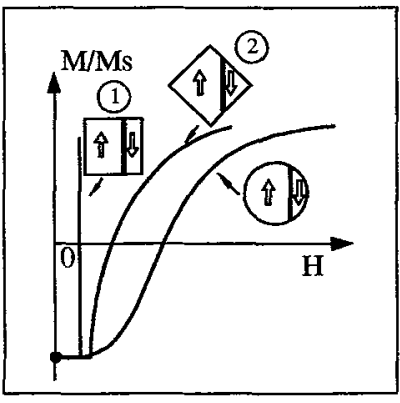

c)

Figure $1:$ a) Elements of calculation of both the magnetic field and the magnetization in the spherical grain. Angles $\theta 0$ and $\theta$ define the domain wall positions I and P. Angle $\alpha$ defines the position with respect to the remanent state (I). $\rho$ is a radius of the curvature. In this condition, the field $\mathrm{H}$ is simply expressed by the formulation (1), b) Example of simulation of both the initial and any magnetization curve [Eqs.(1) and (2)]. c) Evidence of the grain shape influence on the magnetization curve outlines : a relevant parameter to take the notion of magnetic hardness into account.

However, for a quantitative modelling of hysteresis loops, it seems to be not truly consistent especially when the investigated field range is enlarged significantly. We have been led to introduce as a new variable, namely the shape of the grain model (at constant volume) as a function of the excitation magnitude. The ellipsoid has been retained for this purpose. A test have been achieved on a series of loops of materials known to have a "quasi perfect" grain structure with respect to the magnetic-ring concept [demagnetising fields are weak enough to be neglected (fig.2-a)]. A satisfactory result (fig.2-b) is obtained when the field calculations are made on ellipsoids varying as a function of the remanent magnetization. A linear dependence between the ellipsoid changes and the magnetization level has been established. Prolate ellipsoid is suitable for low excitation magnitude while it progressively becomes oblate to limite the wall mobility.

The next stage will be the introduction of a supplementary parameter to take the local demagnetising fields into account.

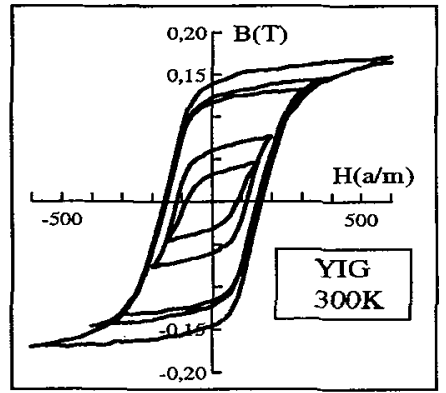

a)

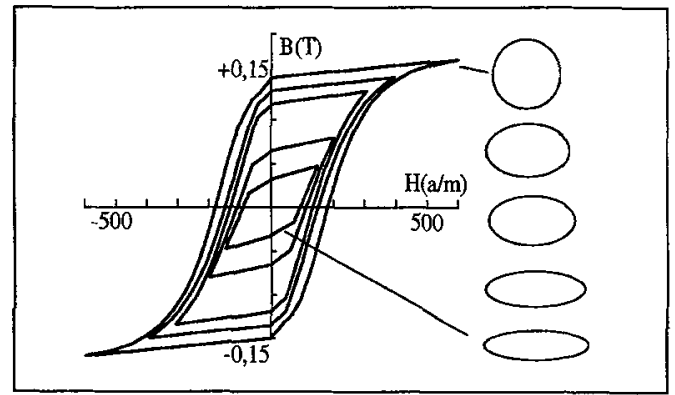

b)

Figure 2 : Theoretical reconstitution (b) of a series of actual loops (a) by using a variable ellipsoid grain, and the following quantitative parameters : Ms $=0.178 \mathrm{~T}, \gamma=9.510^{-5} \mathrm{~J} / \mathrm{m}^{2}, \mathrm{f}=1.3510^{-5} \mathrm{~J} / \mathrm{m}^{2}$. As an example the ellipsoid axes corresponding to the smaller loop are $3.8 \mu \mathrm{m}$, $1.2 \mu \mathrm{m}$ (experimental mean radius of the microstructure: $2.5 \mu \mathrm{m}$ ).

\section{References}

[1] A. Globus, Thesis Univ de Paris (1963) pp 88

[2] M. Guyot, A. Globus, Phys. Status Solidi B 59 (1973) pp 447-454.

[3] M. Le Floc'h, J .Appl. Phys., 67(1) (1990) pp 405-408

[4] F. Liorzou, A.M. Konn and M. Le Floc'h, JMMM, 140-144 (1995) pp 1887-1888

[5] M. Rouadhi, M. Guyot, V. Cagan and R.Krishnan, IEEE Trans on mag, vol.29,No.6,nov1993 pp 3502-3504 